\title{
Contribution of astrocytes to neurovascular coupling in the spinal cord of the rat
}

\author{
Thierry Paquette ${ }^{1,2}$, Mathieu Piché ${ }^{1,2}$ and Hugues Leblond $d^{1,2^{*}}$ (])
}

\begin{abstract}
Functional magnetic resonance imaging (fMRI) of the spinal cord relies on the integrity of neurovascular coupling (NVC) to infer neuronal activity from hemodynamic changes. Astrocytes are a key component of cerebral NVC, but their role in spinal NVC is unclear. The objective of this study was to examine whether inhibition of astrocyte metabolism by fluorocitrate alters spinal NVC. In 14 rats, local field potential (LFP) and spinal cord blood flow (SCBF) were recorded simultaneously in the lumbosacral enlargement during noxious stimulation of the sciatic nerve before and after a local administration of fluorocitrate $(N=7)$ or saline $(N=7)$. Fluorocitrate significantly reduced SCBF responses $(p<0.001)$ but not LFP amplitude ( $p=0.22)$ compared with saline. Accordingly, NVC was altered by fluorocitrate compared with saline $(p<0.01)$. These results support the role of astrocytes in spinal NVC and have implications for spinal cord imaging with fMRI for conditions in which astrocyte metabolism may be altered.
\end{abstract}

Keywords: Astrocyte, Fluorocitrate, Spinal cord, Neurovascular coupling, Blood flow, Local field potential

\section{Introduction}

The non-invasive assessment of spinal cord functions by neuroimaging methods has contributed to the advancement of basic and clinical neuroscience [34, 48]. Recent studies have shown that spinal cord activity induced by painful stimuli can be assessed by functional magnetic resonance imaging (fMRI) [38, 43]. However, these fMRI methods rely on the blood oxygen level-dependent signal (BOLD), a hemodynamic response used to infer the underlying neuronal activity [19], a link referred to as the neurovascular coupling (NVC). Thus, it is essential to understand NVC properties and mechanisms to improve spinal cord fMRI data interpretation and validity. Although, previous studies have examined spinal NVC [27, 28, 33], its mechanisms remain unclear.

In the brain, the NVC is regulated by multiple mechanisms and cell types that are described as the neurovascular unit $[8,17,25]$. In addition to neurons and

*Correspondence: hugues.leblond@uqtr.ca

${ }^{1}$ Department of Anatomy, Université du Québec À Trois-Rivières, 3351 Boulevard des Forges, C.P. 500, Trois-Rivières, QC G9A 5H7, Canada

Full list of author information is available at the end of the article pericytes, astrocytes contribute to blood flow regulation, acting as a mediator between neuronal populations and their surrounding blood vessels $[4,13,23,36$, $41,51]$. These findings are corroborated with supraspinal BOLD fMRI experiences where they manipulate astrocyte activity with optogenetic [42], pharmacological [15] and stimulation paradigm [7]. In response to the release of glutamate by neurons, intracellular $\mathrm{Ca}^{2+}$ increases in astrocytes, which in turn causes the release of vasodilator agents such as epoxyeicosatrienoic acids and prostaglandin E2 [1, 13, 23, 51]. When the locus coeruleus (LC) is activated, the release of noradrenaline also increases intracellular $\mathrm{Ca}^{2+}$ in astrocytes [3], which implies that the NVC unit may produce different responses depending on the origin of neuronal activity, stimulation characteristics, or brain-state [47].

In spite of the critical role of the neurovascular unit in cerebral blood flow regulation, the components of the spinal cord neurovascular unit have never been examined. This seems essential, especially for the validation of spinal fMRI, because some discrepancies have been reported between spinal and cerebral NVC [11, 21, 28, $33,45]$. In contrast to cortical NVC, spinal NVC is not 
affected by isoflurane anesthesia and by large fluctuations in mean arterial pressure during nociceptive stimulation [28, 33]. In addition, astrocytes contribute to autoregulation during arterial pressure changes [12] and they are sensitive to isoflurane [35] in the brain. Thus, their contribution to NVC regulation in the spinal cord may differ, but this remains unclear.

In previous studies, fluorocitrate has been used to determine the roles of astrocytes in the central nervous system and to test neuronal function in the absence astrocyte activity [24, 50]. Astrocytes selectively uptake fluorocitrate, which inhibits aconitase, an enzyme in the Krebs cycle, which in turn inhibits astrocyte metabolic activity $[6,9,29]$. The inhibition is observable $30 \mathrm{~min}$ after the application of fluorocitrate [16] with a maximum effect after $4 \mathrm{~h}[9,29]$. Depending on fluorocitrate concentration, astrocyte inhibition may be reversible [29]. At high doses, however, (over $2 \mathrm{nmol}$ ), the effects are irreversible and even lead to degeneration of neurons [29].

The objective of the present study was to examine the contribution of astrocytes to the spinal cord NVC during noxious stimulation. Based on the critical role of astrocytes in the neurovascular unit of the brain, we hypothesized that astrocyte inhibition by fluorocitrate would reduce SCBF responses without affecting neuronal activity, therefore altering the NVC.

\section{Methods}

\section{Animals and surgical procedures}

Experiments were performed on 14 male Wistar rats (body weight: 320-450 g; age: 18-22 weeks; Charles River Laboratories, Saint-Constant, Québec, Canada). Animals were housed in the animal facilities of Université du Québec à Trois-Rivières with access to food and water ad libitum. A light-dark cycle of 14-10 h was maintained. All animals were in good health on the day of the experiment. The 14 rats were assigned to the fluorocitrate group $(N=7)$ or the control group $(N=7)$. Surgical procedures were conducted under isoflurane anesthesia $(2.5 \%)$ as described previously $[28,33]$. The depth of anesthesia was confirmed by a stable mean arterial pressure (MAP) and was assessed routinely by paw pinching (withdrawal reflex). Rectal temperature was monitored and maintained at $37.5 \pm 0.5{ }^{\circ} \mathrm{C}$ with a custom-made temperature control system. The animal was ventilated mechanically (SAR-830/P 123 Ventilator, CWE Inc., Ardmore, PA, USA) using a tracheal cannula. The ventilation parameters were adjusted to maintain an end-tidal $\mathrm{CO}_{2}$ around 3.0\% (Covidien Capnostream 35 Monitor, Covidien, Dublin, Ireland). The MAP was recorded continuously using a cannula inserted into the right carotid artery and connected to a pressure transducer (Harvard
Apparatus, Holliston, MA, USA). For all animals, MAP remained above $70 \mathrm{mmHg}$ during the entire experiment. Intravenous injections were administered in the catheterized right jugular vein. The left sciatic nerve was dissected for electrical stimulation and a laminectomy was performed between T12 and L1 to access the lumbar enlargement for recordings.

\section{Experimental protocol}

After surgical procedures were completed, the multielectrode was inserted in the spinal cord, the laser-Doppler probe was placed on the surface of the spinal cord and isoflurane anesthesia was lowered to $1.5 \%$. After 45 min of rest, continuous recording of LFP and SCBF began. The stimulation protocol consisted of a series of electrical stimuli at graded intensity, ranging between 0.1 and $9.6 \mathrm{~mA}$. The series of stimuli was applied 5 times, once before fluorocitrate or saline administration, and $1 \mathrm{~h}, 2 \mathrm{~h}, 3 \mathrm{~h}$ and $4 \mathrm{~h}$ after their administration. The order of the 8 stimulus intensities was randomized between animals to avoid sequence order effects, but the 5 series were delivered using the same sequence.

\section{Drug preparation and administration}

The fluorocitrate solution was prepared as described by Paulsen et al. [29]. Eight mg of D,L-fluorocitric acid, $\mathrm{Ba}^{3}$ salt (Sigma-Aldrich, Oakville, Canada) was dissolved in $1 \mathrm{ml}$ of $0.1 \mathrm{M} \mathrm{HCl}$. Three drops of $0.1 \mathrm{M} \mathrm{Na}_{2} \mathrm{SO}_{4}$ were added to precipitate $\mathrm{Ba}^{2+} \cdot \mathrm{Na}_{2} \mathrm{HPO}_{4}$ was then added $(2 \mathrm{ml}$ of $0.1 \mathrm{M})$ and the suspension was centrifuged at $1000 \mathrm{~g}$ for $5 \mathrm{~min}$. The supernatant was diluted with $0.9 \%$ $\mathrm{NaCl}$ to the final concentration and the $\mathrm{pH}$ was adjusted to 7.4. The solution $(0.1 \mathrm{ml}$ at $0.01 \mathrm{nmol} / \mu \mathrm{l})$ was applied directly on the surface of the spinal cord between T12 and L1 within a pool made of petroleum jelly. This fluorocitrate concentration was selected based on a previous study showing that a concentration of $1 \mathrm{nmol}$ progressively inhibits astrocytes without affecting neurons [29]. After confirming proper anesthesia, gallamine triethiodide $(20 \mathrm{mg} / \mathrm{kg})$ was injected through the jugular cannula 20 min before the stimulation protocol began to immobilize the animal and ensure stable recordings.

\section{Local field potentials}

A 16-channel microelectrode (Model A1 $\times 16-10$ mm-200-100-177, Neuronexus Technologies Inc., Ann Arbour, Michigan, USA) was inserted into the left lumbar enlargement using a micromanipulator (Model 960, David Kopf Instruments, Tujunga, CA, USA). The microelectrode position was set where electrical stimulation of the sciatic nerve produced multiunit responses in most of the superficial channels (Smartbox, Neuronexus Technologies Inc., Ann Arbour, Michigan, 
USA; band pass: $300-3000 \mathrm{~Hz}$, gain: $192 \mathrm{~V} / \mathrm{V})$. Signal was sampled at $20 \mathrm{kHz}$ with a broad band $(1-10,000 \mathrm{~Hz}$, gain: $192 \mathrm{~V} / \mathrm{V}$ ) (Smartbox, Neuronexus Technologies Inc., Ann Arbour, Michigan, USA) and recorded on a personal computer for offline analyses. Offline signal processing included resampling at $5 \mathrm{kHz}$ and band pass filtering $(1-300 \mathrm{~Hz})$ to obtain LFPs. For each rat, the channel that showed LFP of the greatest amplitude in the superficial layers of the spinal cord was selected for further analyses (see "Data analyses").

\section{Spinal cord blood flow}

Spinal cord blood flow (SCBF) was recorded with a laserDoppler probe (Micro-needle probe TSD145, Biopac systems, Goleta, CA, USA). The probe was placed on the spinal cord surface, as close as possible from the microelectrode, carefully avoiding large blood vessels. SCBF was sampled at $100 \mathrm{~Hz}$ with a time constant of $3 \mathrm{~s}$ and was recorded on a computer for offline analyses (Power 1401 acquisition system, Cambridge Electronic Design, Cambridge, UK).

\section{Fluorocitrate effect on vasculature}

To test the effect of fluorocitrate on smooth muscle cells of the vasculature, we applied $1 \mathrm{nmol}$ of fluorocitrate on arterioles located in the neck muscles where there is no astrocyte. The vessel diameter was recorded with a HD camera connected to a binocular, with an objective of $40 \times$. The diameter of the arterioles $(N=9$ in two rats) was analyzed offline with 14 time points (every $20 \mathrm{~min}$ ) over a period of $4 \mathrm{~h}$ (ImageJ software). On three of these arterioles, we measured blood flow fluctuations using the same laser-Doppler probe over $4 \mathrm{~h}$.

\section{Electrical stimulation of the sciatic nerve}

Electrical stimulation was applied to the sciatic nerve using a custom-made bipolar hook electrode and a constant-current stimulator (Model DS7A, Digitimer Ltd, Welwyn Garden city, UK). Stimulation consisted of 10-s trains of 1-ms pulses delivered at $5 \mathrm{~Hz}$. The intertrain interval of $55 \mathrm{~s}$ allowed physiological parameters to return to baseline values. Intensity was set for each train at $0.1,0.15,0.3,0.6,1.2,2.4,4.8$, or $9.6 \mathrm{~mA}$.

\section{Data analyses}

LFP, SCBF and MAP data were analyzed using Spike2 software (Cambridge Electronic Design, Cambridge, UK, version 6.15). For the quantification of LFP amplitude, the peak-to-peak value of averaged potentials (50 responses induced by the stimulus train of $10 \mathrm{~s}$ at $5 \mathrm{~Hz}$ ) was extracted with a custom-made Spike2 script within a 50-ms window following stimulus onset. For SCBF and MAP changes, the onset-to-peak value was extracted for each stimulus intensity within a 30-s window and response amplitude was calculated as the change relative to the mean signal value for the $30 \mathrm{~s}$ artifact-free baseline preceding stimulus onset. MAP responses were calculated as the raw change $(\mathrm{mm} \mathrm{Hg})$ while SCBF responses were calculated as percent change. The SCBF and LFP values were transformed into $T$ scores for standardization to calculate the neurovascular coupling, indexed by the SCBF/LFP ratio.

\section{Statistical analyses}

All results are expressed as means \pm SEM. Statistical analyses were performed with Statistica (TIBCO software Inc. 2017. Statistica version 13) with a significance threshold of $p \leq 0.05$. The effect size is reported as partial eta-squared $\left(\eta_{p}^{2}\right)$. The sample size was estimated with a power calculation using G*Power v3.0.10 (G*Power, Kiel, Germany). Based on a conservative effect size ranging between $\eta_{p}^{2}=0.1-0.2$, an $\alpha$ of 0.05 , and a power of 0.8 , we obtained a required sample size ranging between 4 and 7 animals per group. To obtain the most reliable and reproducible results, we used 7 animals per group.

MAP, SCBF, LFP amplitude as well as neurovascular coupling ratios were compared between groups (fluorocitrate vs saline) using Greenhouse-Geisser corrected mixed ANOVAs, with intensity $(0.1,0.15,0.3,0.6,1.2$, 2.4, 4.8, $9.6 \mathrm{~mA}$ ) and time (baseline, $1 \mathrm{~h}, 2 \mathrm{~h}, 3 \mathrm{~h}, 4 \mathrm{~h}$ ) as repeated factors. Significant effects were then decomposed with planned contrasts to test a priori hypotheses.

\section{Results}

\section{Mean arterial pressure}

An individual example of MAP responses is presented in Fig. 1 and the average MAP changes are presented in Fig. 2. Sciatic nerve stimulation produced intensitydependent MAP increases $\left(F_{7,84}=125.0, p<0.001\right.$; $\left.\eta_{p}^{2}=0.91\right)$. These changes were stable and comparable between baseline and other time points $\left(F_{4,48}=1.27\right.$, $\left.p=0.29 ; \eta_{p}^{2}=0.09\right)$. Moreover, MAP changes were not significantly different between groups over time $\left(F_{4,48}=0.27, p=0.89 ; \eta_{p}^{2}=0.02\right)$ or across stimulation intensities $\left(F_{7,84}=0.08, p=1 ; \eta_{p}^{2}=0.01\right)$. This indicates that fluorocitrate did not alter MAP changes. The stability of MAP changes over $4 \mathrm{~h}$ also confirms that physiological conditions remained stable during the entire experiment.

\section{Spinal cord blood flow}

SCBF responses are presented in Fig. 3 and an individual example is also presented in Fig. 1. Electrical stimulation produced intensity-dependent SCBF increases $\left(F_{7,84}=46.5, p<0.001 ; \eta_{p}^{2}=0.79\right)$. These increases were significantly different between groups 

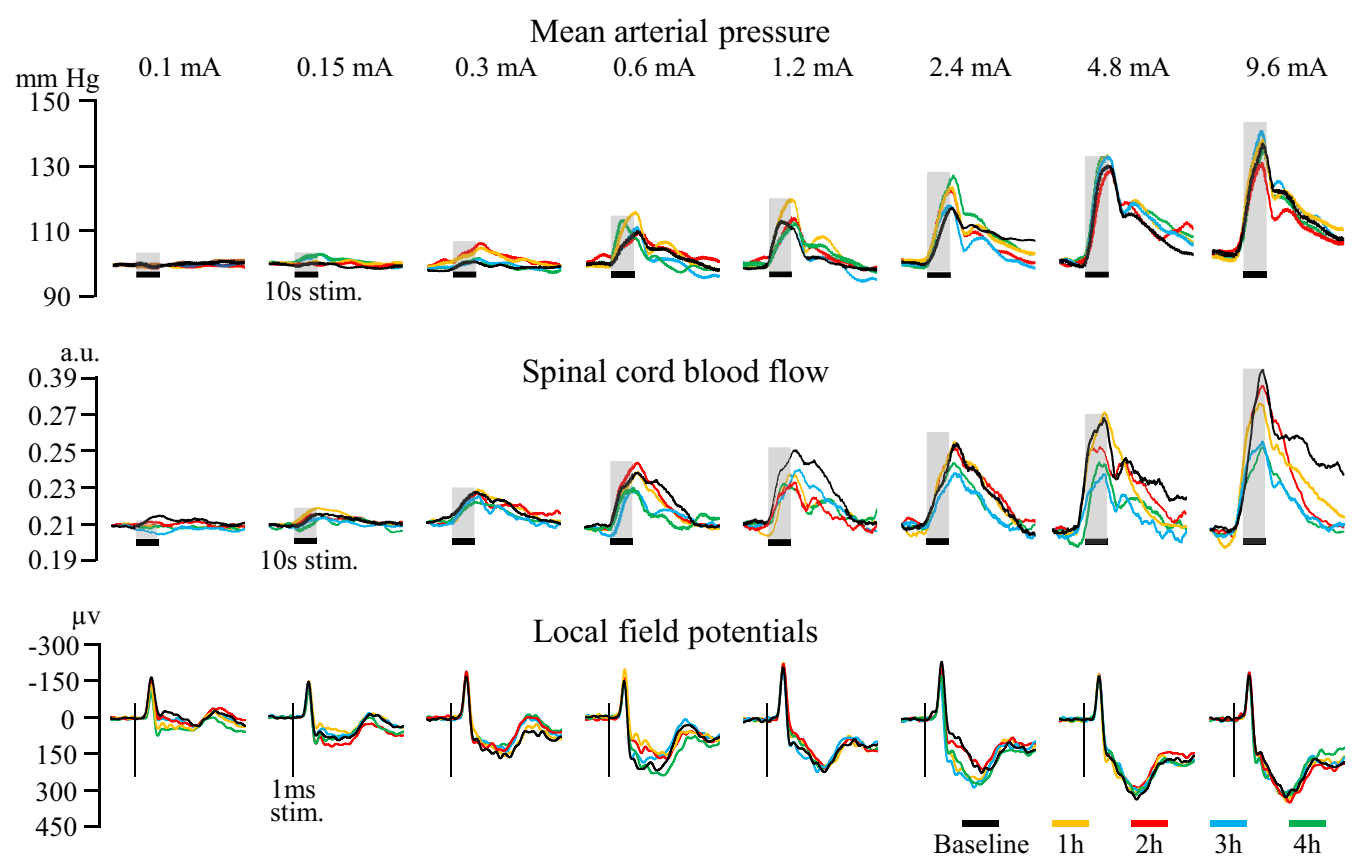

Fig. 1 Individual example of physiological recordings. Representative recordings of MAP, SCBF and LFP responses for the eight stimulus intensities every hour, in one rat that received fluorocitrate. MAP and SCBF responses are a response to a single stimulus. LFP responses represent a mean of 50 responses. The stimulation produced intensity-dependent increases in MAP that remained stable over time and unaffected by fluorocitrate. The stimulation also produced intensity-dependent increases in SCBF. However, response amplitude progressively decreased over time due to the exposure to fluorocitrate. As for LFP, the expected negative and positive deflections were observed with an intensity-dependent amplitude. The peak-to peak amplitude of these deflections was stable over time and unaffected by fluorocitrate. The shaded areas with a horizontal black line (MAP and SCBF) indicate stimulus duration. The vertical grey bars (LFP) indicate the stimulus delivery (one of the 1 ms pulses from the train of 50 pulses)

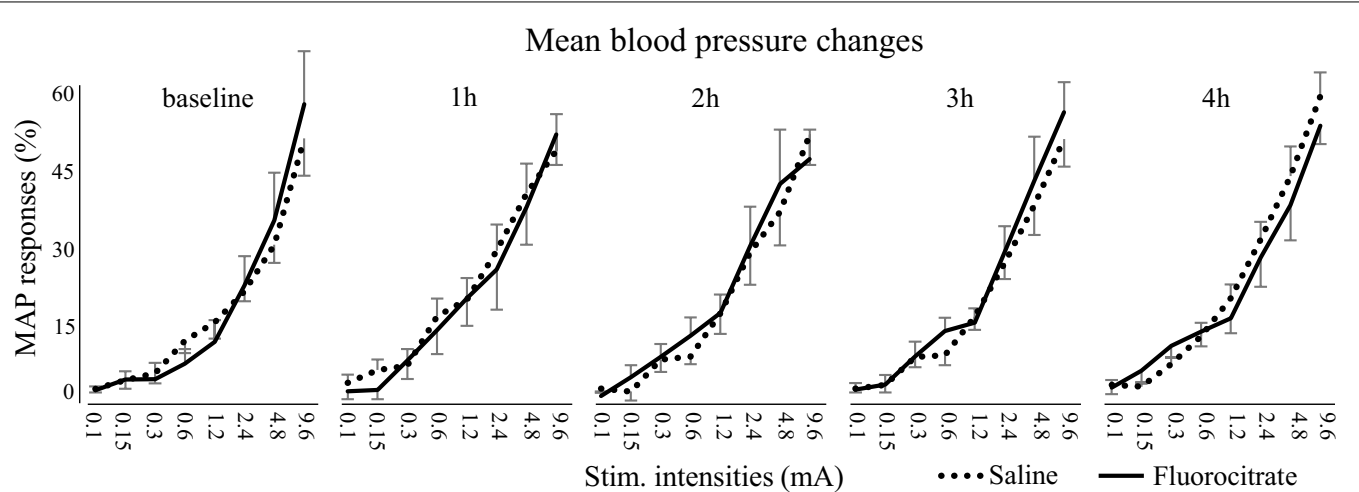

Fig. 2 Sciatic nerve stimulation produced intensity-dependent increases in mean arterial pressure $(p<0.001)$. Both groups showed similar blood pressure responses between intensities and over time $(p<0.8) . N=7$ for each group. Error bars indicate SEM

over time $\left(F_{4,48}=6.6, p<0.001 ; \eta^{2}=0.36\right)$. Planned contrasts revealed that the effects of fluorocitrate on the SCBF changes were significantly different compared with saline at $1 \mathrm{~h}, 2 \mathrm{~h}, 3 \mathrm{~h}$ and $4 \mathrm{~h}$ compared with the baseline (all $p<0.05$ ). As expected, the effect of fluorocitrate progressively increased, as shown by greater reduction of SCBF changes with time (linear trend: $p<0.001$ ), while no such trend was observed with saline $(p=0.6)$. On average, for all intensities combined, fluorocitrate reduced SCBF changes by $23.8 \pm 9.4 \%$ at $1 \mathrm{~h}$, by $31.2 \pm 14.1 \%$ at $2 \mathrm{~h}$, by $40.2 \pm 11.9 \%$ at $3 \mathrm{~h}$ and by $38.3 \pm 10.5 \%$ at $4 \mathrm{~h}$ 
Progressive decline of spinal cord blood flow responses induced by astrocyte inhibition

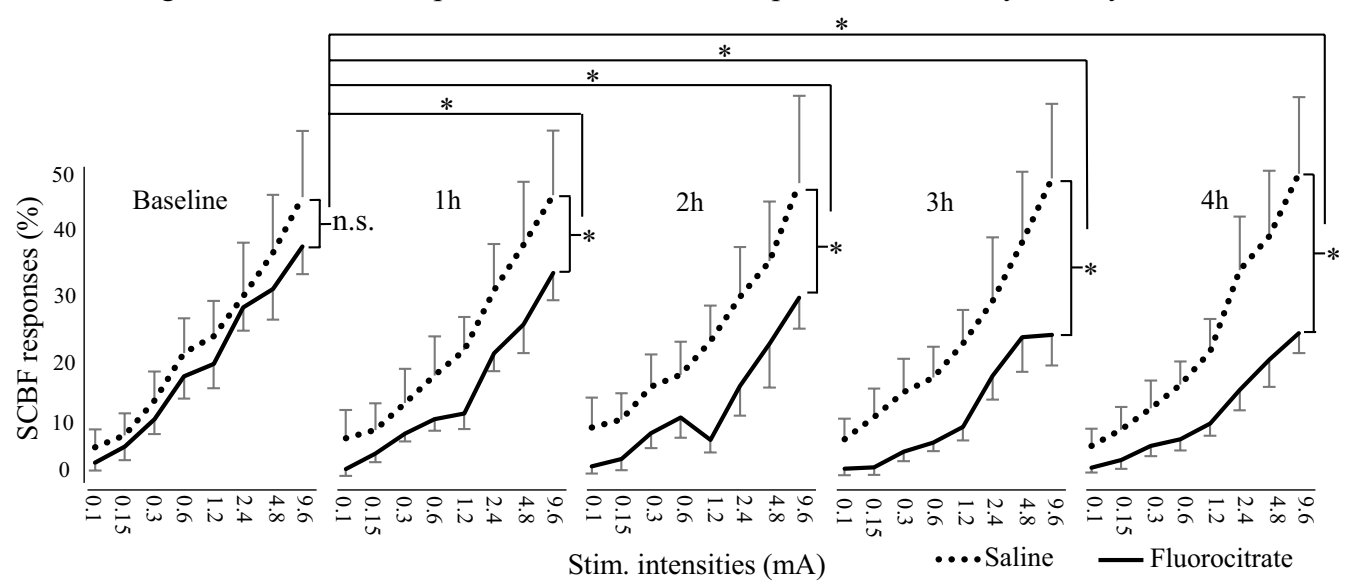

Fig. 3 Electrical stimulation of the left sciatic nerve evoked intensity-dependent SCBF responses $(p<0.001)$. These increases were significantly different between the fluorocitrate (solid line) and control (dotted line) group over time $(p<0.001) . N=7$ for each group. Error bars indicate SEM. ${ }^{*} p<0.05$

compared with the baseline. In contrast, SCBF changes in the saline group were stable over time with limited fluctuations $(1.2 \pm 11.4 \%$ at $1 \mathrm{~h}, 9.7 \pm 20.0 \%$ at $2 \mathrm{~h}$, $5.8 \pm 15.4 \%$ at $3 \mathrm{~h}$ and $1.0 \pm 13.5 \%$ at $4 \mathrm{~h}$ ).

Baseline SCBF recorded over $30 \mathrm{~s}$ before every stimulation was comparable between groups over time $\left(F_{4,48}=0.99, p=0.4 ; \eta_{p}^{2}=0.07\right)$. On average, in comparison to baseline values recorded before fluorocitrate administration, baseline SCBF varied by $3.2 \pm 8.0 \%$ at $1 \mathrm{~h}$, by $1.9 \pm 9.9 \%$ at $2 \mathrm{~h}$, by $3.5 \pm 11.1 \%$ at $3 \mathrm{~h}$ and by $-1.5 \pm 11.0 \%$ at $4 \mathrm{~h}$. Comparable changes were observed in the saline group: $0.9 \pm 6.8 \%$ at $1 \mathrm{~h}$, by $4.8 \pm 5.9 \%$ at 2 h, by $1.6 \pm 7.4 \%$ at $3 \mathrm{~h}$ and by $3.8 \pm 5.2 \%$ at $4 \mathrm{~h}$.

\section{Spinal cord local field potentials}

Results for LFP amplitude are presented in Fig. 4 an individual example is also presented in Fig. 1. LFP amplitude increased with stimulus intensity $\left(F_{7,84}=20.5, p<0.001\right.$; $\left.\eta_{p}^{2}=0.02\right)$. However, LFP amplitude was not significantly different between groups over time $\left(F_{4,48}=1.5, p=0.22\right.$; $\eta_{p}^{2}=0.1$ ), indicating that astrocyte inhibition by fluorocitrate did not modulate neuronal activity.

\section{Spinal cord neurovascular coupling}

Results for NVC are presented in Fig. 5. NVC was significantly different between groups over time $\left(F_{4,48}=4.8\right.$, $\left.p<0.01 ; \eta_{p}^{2}=0.28\right)$. Planned contrasts revealed that fluorocitrate significantly reduced NVC at $2 \mathrm{~h}, 3 \mathrm{~h}$ and $4 \mathrm{~h}$ compared with the baseline (all $p \leq 0.04$ ) consistent

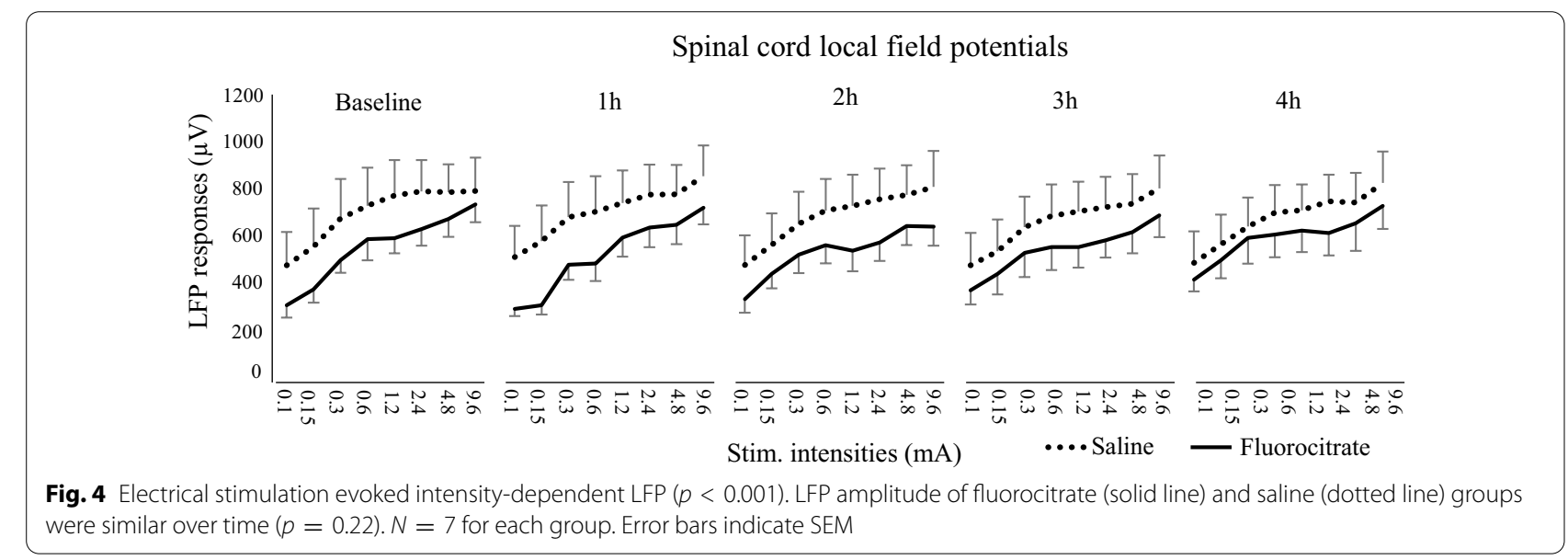


Progressive decline of spinal cord neurovascular coupling induced by astrocyte inhibition

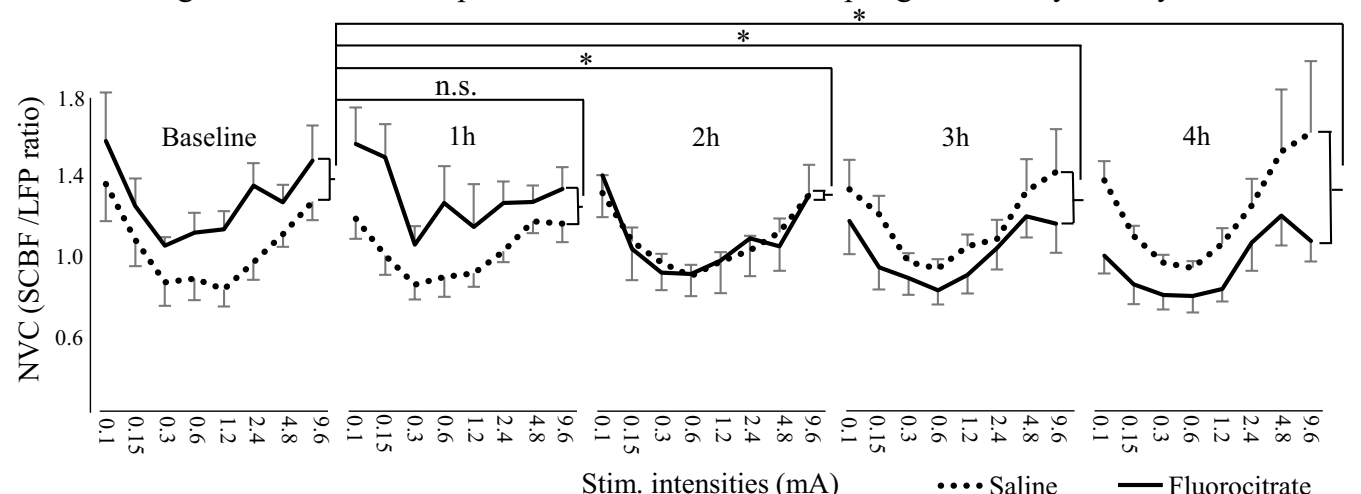

Fig. 5 The neurovascular coupling was calculated as the SCBF/LFP ratio. The coupling was significantly different between the fluorocitrate (solid line) and control (dotted line) group over time $(p<0.01)$. The progressive decrease of the neurovascular coupling in the fluorocitrate group was significant from $2 \mathrm{~h}$ and afterward following fluorocitrate administration $(p<0.04)$. Error bars $=\mathrm{SEM}^{*}{ }^{*}<0.05$

with the alteration of SCBF and the lack of effect on LFP amplitude. Like SCBF, NVC progressively decreased with time (linear trend: $p=0.04$ ), while no such trend was observed with saline $(p=0.17)$.

\section{Fluorocitrate effects on vasculature}

To confirm the lack of effects of fluorocitrate on vascular smooth muscles, fluorocitrate was applied on arterioles located in the neck muscles which are devoid of surrounding astrocytes. Arterioles diameter did not change significantly over $4 \mathrm{~h}$ for the 14 time points $\left(F_{13,104}=1.2\right.$, $\left.p=0.3 ; \eta_{p}^{2}=0.12\right)$. On average, in comparison to the baseline diameter measured before fluorocitrate administration, the diameter varied by $1.6 \pm 1.0 \%$ at $1 \mathrm{~h}$, by $1.2 \pm 0.9 \%$ at $2 \mathrm{~h}$, by $0.3 \pm 1.6 \%$ at $3 \mathrm{~h}$ and by $1.0 \pm 0.6 \%$ at $4 \mathrm{~h}$. Arterial blood flow of three of these arterioles also remained stable over time after fluorocitrate administration: Friedman ANOVA $\left(\chi^{2}(4)=2.7, p=0.6\right)$. On average, in comparison to the baseline arterial blood flow measured before fluorocitrate administration, the blood flow varied by $-0.1 \pm 3.9 \%$ at $1 \mathrm{~h}$, by $2.1 \pm 2.2 \%$ at $2 \mathrm{~h}$, by $2.9 \pm 3.0 \%$ at $3 \mathrm{~h}$ and by $-0.8 \pm 4.9 \%$ at $4 \mathrm{~h}$. These results demonstrate that fluorocitrate does not act on the vascular tissue.

\section{Discussion}

The present results confirm our hypothesis and show that fluorocitrate administration decreases SCBF responses without affecting neuronal activity. Indeed, astrocyte inhibition by fluorocitrate reduced SCBF responses by up to $40 \%$ while neuronal activity was unaffected. This indicates that astrocytes contribute to the regulation of NVC in the spinal cord. This finding is consistent with the contribution of astrocytes to NVC reported for the cerebral cortex $[2,51]$. This also suggests that although the mechanisms of blood flow regulation are different between the brain and the spinal cord, astrocytes seem to play a similar role in maintaining a tight relationship between changes in neuronal activity and blood flow.

\section{Effects of astrocyte inhibition on blood flow responses and neuronal activity}

In the present study, noxious stimuli of relatively long duration (10 s) were used. The results indicate that astrocyte inhibition by fluorocitrate decreased SCBF responses to these stimuli. However, it is not clear if this applies to stimuli of shorter duration. Indeed, stimulusevoked calcium changes in astrocytes may occur 3-4 s after stimulus onset in the visual cortex [35]. This suggests that astrocytes do not initiate the NVC and the stimulus-evoked blood flow responses [5, 44]. Accordingly, localized vascular responses in the barrel cortex occur without astrocyte activation during a 5-s whisker stimulation protocol [36]. Consistent with this idea, blood flow responses evoked by stimuli of relatively short duration may be less affected or not affected at all by astrocyte inhibition in the spinal cord so the present results may not be generalizable to noxious stimuli of shorter duration.

It should be noted that SCBF responses were not completely abolished by astrocyte inhibition, as expected. Indeed, although the astrocytes are a key component of the neurovascular unit, they are not the sole communication pathway between neurons and blood vessels [4]. Changes in extracellular $\mathrm{K}^{+}$generated by neuronal activity hyperpolarize capillary endothelial cells, which produces vasodilation of arterioles [20]. In the cortex, PGE2 released by pyramidal cells and NO released by NOS 
interneurons also contribute to the NVC [4]. It remains unclear whether this applies to the spinal cord, but it has been shown that NOS interneurons are present in high concentration in the dorsal horn of the spinal cord [46]. Thus, the direct communication between neurons and endothelial cells [25] and NOS interneurons may contribute to residual SCBF responses after astrocyte inhibition.

In addition to their vascular function, astrocytes provide neurons with nutriment such as lactate [37] and they contribute to the uptake and release of glutamate/ glutamine [22]. Astrocyte inhibition by fluorocitrate also reduces these functions, which may in turn affect neuronal function. However, this is unlikely to affect the present results since LFP amplitude was stable over the $4 \mathrm{~h}$ of recording and was not significantly different between the fluorocitrate and saline groups. Moreover, previous studies indicate that fluorocitrate does not produce neuronal damage up to $24 \mathrm{~h}$ after its administration if it is not associated with neuronal stressors such as spreading depression [18]. In the present study, stimuli produced phasic neuronal activity and were applied with a relatively long inter-stimulus interval (55 s). This prevents tonic activity that may lead to neuronal stress as in spreading depression. In addition, histological examination of neurons after $4 \mathrm{~h}$ of fluorocitrate exposure has shown no damage, which became observable only after $8 \mathrm{~h}$ [16].

\section{Progressive astrocyte inhibition by fluorocitrate}

Astrocytes uptake fluorocitrate selectively [6, 26, 49]. In the astrocyte, fluorocitrate blocks the Krebs cycle, which alters the production of ATP [31] and gradually decreases metabolic activity. This progressive inhibition of astrocytes by fluorocitrate was reported previously [9, 29]. In the present study, the inhibition of astrocytes was reflected in a progressive decrease in SCBF responses over time. In comparison to control SCBF responses, SCBF responses decreased by $23.8 \%$ one hour after fluorocitrate administration. The decrease in SCBF responses peaked after $3 \mathrm{~h}(40.2 \%)$ and was similar after $4 \mathrm{~h}$ (38.3\%). This gradual effect is in agreement with the decrease of glutamine (only synthesized by astrocytes) $30 \mathrm{~min}$ after fluorocitrate treatment and the lowest level of glutamine at $3 \mathrm{~h}$ [16]. Similarly, fluorocitrate administration produces time-dependent changes of cAMP in astrocytes (peak of $94 \%$ at $2 \mathrm{~h}$ ) [39] and in amino acid, with a maximal effect between 2 and $4 \mathrm{~h}$ [29].

\section{Limitation and further direction}

In the present study, the conclusion on astrocyte inhibition by fluorocitrate relies on its effect on SCBF responses and the lack of effect on neuronal activity. Although the time course of the effect of fluorocitrate on SCBF is consistent with its expected effects on astrocytes [16, 29], with no effect on neuronal activity, future studies are needed to confirm astrocyte inhibition with a direct measure of astrocyte activity. Alternatively, astrocyte activity may be manipulated specifically with chemogenetic methods $[10,14]$.

Another limitation to consider is that pericytes contribute to the NVC in the brain [30] (review [40]). The present results may thus be explained by an indirect effect of fluorocitrate on pericytes through astrocyte inhibition since astrocytes partly regulate blood vessel diameter through communication with pericytes [40]. Nonetheless, it remains that the decreased SCBF responses are unlikely to be produced by a direct effect of fluorocitrate on pericytes.

\section{Conclusions}

In conclusion, the present study indicates that astrocytes contribute to the regulation of NVC in the spinal cord. These results have implications for the use of spinal fMRI for clinical conditions in which astrocyte functions are altered, including amyotrophic lateral sclerosis [32].

\section{Abbreviations \\ LFP: Local field potentials; MAP: Mean arterial pressure; NVC: Neurovascular coupling; SCBF: Spinal cord blood flow.}

\section{Acknowledgements}

Not applicable.

\section{Authors' contributions}

TP, MP and HL designed the research and wrote/edited the manuscript. TP and $\mathrm{HL}$ performed the experiments and collected the data. TP, MP analyzed the data. All authors read and approved the final manuscript.

\section{Funding}

This work was supported by Grants from the Natural Science and Engineering Research Council of Canada (MP: 06559, HL: 05403). The contribution of MP was supported by the Fonds de recherche du Québec en Santé (FRQS). The contribution of TP was supported by a scholarship from the Natural Science and Engineering Research Council of Canada.

\section{Availability of data and materials}

The datasets used and/or analyzed during the current study are available from the corresponding author on reasonable request.

\section{Declarations}

\section{Ethics approval and consent to participate}

All experimental procedures were approved by the animal care committee of Université du Québec à Trois-Rivières and conformed to the Guidelines of the Canadian Council on Animal Care and the Guidelines of the Committee for Research and Ethical Issues of the International Association for the Study of Pain (IASP).

\section{Consent for publication}

Not applicable.

\section{Competing interests}

The authors declare that they have no competing interests. 


\section{Author details}

${ }^{1}$ Department of Anatomy, Université du Québec À Trois-Rivières, 3351 Boulevard des Forges, C.P. 500, Trois-Rivières, QC G9A 5H7, Canada. ${ }^{2}$ CogNAC Research Group, Université du Québec À Trois-Rivières, Trois-Rivières, QC G9A $5 \mathrm{H} 7$, Canada.

Received: 15 February 2021 Accepted: 19 May 2021 Published online: 28 May 2021

\section{References}

1. Alkayed NJ, Birks EK, Narayanan J, Petrie KA, Kohler-Cabot AE, Harder DR (1997) Role of P-450 arachidonic acid epoxygenase in the response of cerebral blood flow to glutamate in rats. Stroke 28(5):1066-1072

2. Attwell D, Buchan AM, Charpak S, Lauritzen M, MacVicar BA, Newman EA (2010) Glial and neuronal control of brain blood flow. Nature 468(7321):232-243. https://doi.org/10.1038/nature09613

3. Bekar LK, He W, Nedergaard M (2008) Locus coeruleus a-adrenergicmediated activation of cortical astrocytes in vivo. Cereb Cortex 18(12):2789-2795. https://doi.org/10.1093/cercor/bhn040

4. Cauli B, Hamel E (2018) Brain perfusion and astrocytes. Trends Neurosci 41(7):409-413. https://doi.org/10.1016/j.tins.2018.04.010

5. Drew PJ (2019) Vascular and neural basis of the BOLD signal. Curr Opin Neurobiol 58:61-69. https://doi.org/10.1016/j.conb.2019.06.004

6. Fonnum $F$, Johnsen A, Hassel B (1997) Use of fluorocitrate and fluoroacetate in the study of brain metabolism. Glia 21(1):106-113. https://doi. org/10.1002/(SICI)1098-1136(199709)21:1\%3c106::AID-GLIA12\%3e3.0. $\mathrm{CO} ; 2-\mathrm{W}$

7. Gu X, Chen W, Volkow ND, Koretsky AP, Du C, Pan Y (2018) Synchronized astrocytic $\mathrm{Ca}^{(2+)}$ responses in neurovascular coupling during somatosensory stimulation and for the resting state. Cell Rep 23(13):3878-3890. https://doi.org/10.1016/j.celrep.2018.05.091

8. Harder DR, Zhang C, Gebremedhin D (2002) Astrocytes function in matching blood flow to metabolic activity. Physiology 17(1):27-31. https://doi.org/10.1152/physiologyonline.2002.17.1.27

9. Hassel B, Paulsen RE, Johnsen A, Fonnum F (1992) Selective inhibition of glial cell metabolism in vivo by fluorocitrate. Brain Res 576(1):120-124

10. Hirbec H, Déglon N, Foo LC, Goshen I, Grutzendler J, Hangen E, Kreisel T, Linck N, Muffat J, Regio S, Rion S, Escartin C (2020) Emerging technologies to study glial cells. Glia 68(9):1692-1728. https://doi.org/10.1002/glia. 23780

11. Jeffrey-Gauthier R, Guillemot JP, Piche M (2013) Neurovascular coupling during nociceptive processing in the primary somatosensory cortex of the rat. Pain 154(8):1434-1441. https://doi.org/10.1016/j.pain.2013.04.042

12. Kim KJ, Iddings JA, Stern JE, Blanco VM, Croom D, Kirov SA, Filosa JA (2015) Astrocyte contributions to flow/pressure-evoked parenchymal arteriole vasoconstriction. J Neurosci 35(21):8245-8257. https://doi.org/ 10.1523/jneurosci.4486-14.2015

13. Koehler RC, Roman RJ, Harder DR (2009) Astrocytes and the regulation of cerebral blood flow. Trends Neurosci 32(3):160-169. https://doi.org/10. 1016/j.tins.2008.11.005

14. Kohro Y, Matsuda T, Yoshihara K, Kohno K, Koga K, Katsuragi R, Oka T, Tashima R, Muneta S, Yamane T, Okada S, Momokino K, Furusho A, Hamase K, Oti T, Sakamoto H, Hayashida K, Kobayashi R, Horii T, Hatada I, Tozaki-Saitoh H, Mikoshiba K, Taylor V, Inoue K, Tsuda M (2020) Spinal astrocytes in superficial laminae gate brainstem descending control of mechanosensory hypersensitivity. Nat Neurosci 23(11):1376-1387. https://doi.org/10.1038/s41593-020-00713-4

15. Komaki Y, Debacker C, Djemai B, Ciobanu L, Tsurugizawa T, Le Bihan D (2020) Differential effects of aquaporin-4 channel inhibition on BOLD fMRI and diffusion $\mathrm{fMRI}$ responses in mouse visual cortex. PLOS ONE 15(5):e0228759. https://doi.org/10.1371/journal.pone.0228759

16. Largo C, Cuevas P, Somjen G, Martin del Rio R, Herreras O (1996) The effect of depressing glial function in rat brain in situ on ion homeostasis, synaptic transmission, and neuron survival. J Neurosci 16(3):1219-1229. https://doi.org/10.1523/jneurosci.16-03-01219.1996

17. Lecrux C, Hamel E (2011) The neurovascular unit in brain function and disease. Acta Physiol 203(1):47-59. https://doi.org/10.1111/j.1748-1716. 2011.02256.x
18. Lian XY, Stringer JL (2004) Energy failure in astrocytes increases the vulnerability of neurons to spreading depression. Eur J Neurosci 19(9):24462454. https://doi.org/10.1111/j.0953-816X.2004.03289.x

19. Logothetis NK, Pauls J, Augath M, Trinath T, Oeltermann A (2001) Neurophysiological investigation of the basis of the $\mathrm{fMRI}$ signal. Nature 412(6843):150-157. https://doi.org/10.1038/35084005

20. Longden TA, Dabertrand F, Koide M, Gonzales AL, Tykocki NR, Brayden JE, Hill-Eubanks D, Nelson MT (2017) Capillary K ${ }^{+}$-sensing initiates retrograde hyperpolarization to increase local cerebral blood flow. Nat Neurosci 20(5):717-726. https://doi.org/10.1038/nn.4533

21. Masamoto K, Fukuda M, Vazquez A, Kim SG (2009) Dose-dependent effect of isoflurane on neurovascular coupling in rat cerebral cortex. Eur J Neurosci 30(2):242-250. https://doi.org/10.1111/j.1460-9568.2009. 06812.x

22. McKenna MC (2007) The glutamate-glutamine cycle is not stoichiometric: fates of glutamate in brain. J Neurosci Res 85(15):3347-3358. https:// doi.org/10.1002/jnr.21444

23. Metea MR, Newman EA (2006) Glial cells dilate and constrict blood vessels: a mechanism of neurovascular coupling. J Neurosci 26(11):28622870. https://doi.org/10.1523/jneurosci.4048-05.2006

24. Milligan ED, Twining C, Chacur M, Biedenkapp J, O'Connor K, Poole S, Tracey K, Martin D, Maier SF, Watkins LR (2003) Spinal Glia and Proinflammatory cytokines mediate mirror-image neuropathic pain in rats. J Neurosci 23(3):1026-1040. https://doi.org/10.1523/jneurosci.23-03-01026. 2003

25. Muoio V, Persson PB, Sendeski MM (2014) The neurovascular unit-concept review. Acta Physiol 210(4):790-798. https://doi.org/10.1111/apha. 12250

26. Omara F, Sisodia CS (1990) Evaluation of potential antidotes for sodium fluoroacetate in mice. Vet Hum Toxicol 32(5):427-431

27. Paquette T, Jeffrey-Gauthier R, Leblond H, PichÉ M (2018) Functional neuroimaging of nociceptive and pain-related activity in the spinal cord and brain: insights from neurovascular coupling studies. Anat Rec 301(9):1585-1595

28. Paquette T, Leblond H, Piché M (2018) Isoflurane anesthesia does not affect spinal cord neurovascular coupling: evidence from decerebrated rats. J Physiol Sci. https://doi.org/10.1007/s12576-018-0607-7

29. Paulsen RE, Contestabile A, Villani L, Fonnum F (1987) An in vivo model for studying function of brain tissue temporarily devoid of glial cell metabolism: the use of fluorocitrate. J Neurochem 48(5):1377-1385

30. Peppiatt CM, Howarth C, Mobbs P, Attwell D (2006) Bidirectional control of CNS capillary diameter by pericytes. Nature 443(7112):700-704. https://doi.org/10.1038/nature05193

31. Peters RA (1957) Mechanism of the toxicity of the active constituent of Dichapetalum cymosum and related compounds. Adv Enzymol Relat Subj Biochem 18:113-159. https://doi.org/10.1002/9780470122631.ch3

32. Phatnani H, Maniatis T (2015) Astrocytes in neurodegenerative disease. Cold Spring Harb Perspect Biol 7(6):a020628

33. Piché M, Paquette T, Leblond H (2017) Tight neurovascular coupling in the spinal cord during nociceptive stimulation in intact and spinal rats. Neuroscience 355:1-8. https://doi.org/10.1016/j.neuroscience.2017.04. 038

34. Powers JM, loachim G, Stroman PW (2018) Ten key insights into the use of spinal cord fMRI. Brain Sci. https://doi.org/10.3390/brainsci8090173

35. Schummers J, Yu H, Sur M (2008) Tuned responses of astrocytes and their influence on hemodynamic signals in the visual cortex. Science 320(5883):1638-1643. https://doi.org/10.1126/science.1156120

36. Sharma K, Gordon GRJ, Tran CHT (2020) Heterogeneity of sensoryinduced astrocytic $\mathrm{Ca}^{2+}$ dynamics during functional hyperemia. Front Physiol. https://doi.org/10.3389/fphys.2020.611884

37. Sotelo-Hitschfeld T, Niemeyer MI, Mächler P, Ruminot I, Lerchundi R, Wyss MT, Stobart J, Fernández-Moncada I, Valdebenito R, Garrido-Gerter P, Contreras-Baeza Y, Schneider BL, Aebischer P, Lengacher S, San Martín A, Le Douce J, Bonvento G, Magistretti PJ, Sepúlveda FV, Weber B, Barros LF (2015) Channel-mediated lactate release by $\mathrm{K}^{+}$-stimulated astrocytes. J Neurosci 35(10):4168-4178. https://doi.org/10.1523/jneurosci.5036-14. 2015

38. Sprenger C, Finsterbusch J, Büchel C (2015) Spinal cord-midbrain functional connectivity is related to perceived pain intensity: a combined spino-cortical fMRI study. J Neurosci 35(10):4248-4257. https://doi.org/ 10.1523/jneurosci.4897-14.2015 
39. Stone EA, Sessler FM, Weimin L (1990) Glial localization of adenylatecyclase-coupled $\beta$-adrenoreceptors in rat forebrain slices. Brain Res 530(2):295-300. https://doi.org/10.1016/0006-8993(90)91298-U

40. Sweeney MD, Ayyadurai S, Zlokovic BV (2016) Pericytes of the neurovascular unit: key functions and signaling pathways. Nat Neurosci 19(6):771-783. https://doi.org/10.1038/nn.4288

41. Takano T, Tian G-F, Peng W, Lou N, Libionka W, Han X, Nedergaard M (2006) Astrocyte-mediated control of cerebral blood flow. Nat Neurosci 9(2):260

42. Takata N, Sugiura Y, Yoshida K, Koizumi M, Hiroshi N, Honda K, Yano R, Komaki Y, Matsui K, Suematsu M, Mimura M, Okano H, Tanaka KF (2018) Optogenetic astrocyte activation evokes BOLD fMRI response with oxygen consumption without neuronal activity modulation. Glia 66(9):20132023. https://doi.org/10.1002/glia.23454

43. Tinnermann A, Büchel C, Cohen-Adad J (2021) Cortico-spinal imaging to study pain. Neuroimage 224:117439. https://doi.org/10.1016/j.neuro image.2020.117439

44. Tran CHT, Peringod G, Gordon GR (2018) Astrocytes integrate behavioral state and vascular signals during functional hyperemia. Neuron 100(5):1133-1148.e1133. https://doi.org/10.1016/j.neuron.2018.09.045

45. Uchida S, Bois S, Guillemot J-P, Leblond H, Piché M (2017) Systemic blood pressure alters cortical blood flow and neurovascular coupling during nociceptive processing in the primary somatosensory cortex of the rat. Neuroscience 343:250-259. https://doi.org/10.1016/j.neuroscience.2016. 12.014

46. Valtschanoff JG, Weinberg RJ, Rustioni A (1992) NADPH diaphorase in the spinal cord of rats. J Comp Neurol 321(2):209-222. https://doi.org/10. 1002/cne.903210204
47. Wang M, He Y, Sejnowski TJ, Yu X (2018) Brain-state dependent astrocytic $\mathrm{Ca}^{(2+)}$ signals are coupled to both positive and negative BOLD-fMRI signals. Proc Natl Acad Sci U S A 115(7):E1647-e1656. https://doi.org/10. 1073/pnas.1711692115

48. Wheeler-Kingshott CA, Stroman PW, Schwab JM, Bacon M, Bosma R, Brooks J, Cadotte DW, Carlstedt T, Ciccarelli O, Cohen-Adad J, Curt A, Evangelou N, Fehlings MG, Filippi M, Kelley BJ, Kollias S, Mackay A, Porro CA, Smith S, Strittmatter SM, Summers P, Thompson AJ, Tracey I (2014) The current state-of-the-art of spinal cord imaging: applications. Neuroimage 84:1082-1093. https://doi.org/10.1016/j.neuroimage.2013.07.014

49. Willoughby JO, Mackenzie L, Broberg M, Thoren AE, Medvedev A, Sims NR, Nilsson M (2003) Fluorocitrate-mediated astroglial dysfunction causes seizures. J Neurosci Res 74(1):160-166. https://doi.org/10.1002/jnr.10743

50. Yoshioka K, Nisimaru N, Yanai S, Shimoda H, Yamada K (2000) Characteristics of monocarboxylates as energy substrates other than glucose in rat brain slices and the effect of selective glial poisoning - a 31P NMR study. Neurosci Res 36(3):215-226

51. Zonta M, Angulo MC, Gobbo S, Rosengarten B, Hossmann KA, Pozzan T, Carmignoto G (2003) Neuron-to-astrocyte signaling is central to the dynamic control of brain microcirculation. Nat Neurosci 6(1):43-50. https://doi.org/10.1038/nn980

\section{Publisher's Note}

Springer Nature remains neutral with regard to jurisdictional claims in published maps and institutional affiliations.
Ready to submit your research? Choose BMC and benefit from:

- fast, convenient online submission

- thorough peer review by experienced researchers in your field

- rapid publication on acceptance

- support for research data, including large and complex data types

- gold Open Access which fosters wider collaboration and increased citations

- maximum visibility for your research: over $100 \mathrm{M}$ website views per year

At BMC, research is always in progress.

Learn more biomedcentral.com/submissions 